\title{
Peripheral interleukin-1 $\beta$ levels are elevated in chronic tension-type headache patients
}

\author{
Chris Della Vedova PhD ${ }^{1}$, Stuart Cathcart PhD ${ }^{2}$, Alan Dohnalek BLabMed(Hons) ${ }^{1}$, Vanessa Lee BLabMed(Hons) ${ }^{1}$, \\ Mark R Hutchinson $\mathrm{PhD}^{3}$, Maarten A Immink $\mathrm{PhD}^{4}$, John Hayball $\mathrm{PhD}^{1}$
}

\begin{abstract}
C Della Vedova, S Cathcart, A Dohnalek, et al. Peripheral interleukin-1 $\beta$ levels are elevated in chronic tension-type headache patients. Pain Res Manag 2013;18(6):301-306.
\end{abstract}

BACKGROUND: Tension-type headache is the most common form of headache and its chronic form, chronic tension-type headache (CTTH), is one of the most difficult to treat. The etiology of CTTH is not well understood, but is believed to be multifactorial and to vary among individuals. In the present study, the authors sought to identify common mechanisms of CTTH pathology. Empirical studies have implicated various immunomodulatory cytokines as mediators of chronic pain disorders, including CTTH.

OBJECTIVES: To determine the role of peripheral cytokines and genetic factors in the development of CTTH.

METHODS: A panel of cytokines hypothesized to play a role in the pathogenesis of CTTH was measured using cytometric bead arrays and ELISAs in 56 individuals with CTTH and 42 healthy control participants between 18 and 65 years of age.

RESULTS: Levels of interleukin (IL)- $1 \beta$ were significantly elevated in participants diagnosed with CTTH relative to healthy controls, while IL-18 levels were found to be significantly elevated in men with CTTH. Because the levels of these immune mediators were increased in the apparent absence of injury or infection, the authors sought to determine whether genetic changes were responsible for fluctuations in cytokine levels. Polymerase chain reaction and restriction fragment length polymorphism analyses were used to determine individual genotypes at key single nucleotide polymorphism positions in the IL-1B gene. No association was observed between CTTH and single nucleotide polymorphisms in the IL-1 $1 \beta$ gene.

CONCLUSIONS: These findings suggest that increases in key proinflammatory cytokine levels are associated with CTTH and the pathology of the disorder involves sterile neurovascular inflammation.

Key Words: Chronic tension-type headache; Genetics; Inflammation; Interleukin-1 $\beta$; Interleukin-18

$\mathrm{T}$ ension-type headache (TTH) is the most common form of headache and accounts for approximately $80 \%$ of headache diagnoses, yet its etiology remains uncertain (1). It is associated with significant socioeconomic impact through loss of employment productivity and increased health care costs, and with reduced quality of life (2). The chronic form of TTH (CTTH) (headache occurring $>15$ days per month), while less common, is more debilitating, ranking in the WHO's top 10 illnesses according to disability (3).

The pathophysiology of CTTH is largely unknown, although recent models suggest both central and peripheral nervous system mechanisms. It has been suggested that patients with CTTH exhibit reduced excitability of brain stem inhibitory neurons as well as reduced thresholds for nociceptive flexion reflexes and pain tolerance (4). These results suggest an imbalance in central nervous system pain control mechanisms (1). In the peripheral nervous system, it is believed that CTTH is mediated by referred pain from myofascial trigger points mediated by central sensitization (5).

\section{Les taux d'interleukine-1 $\beta$ périphérique sont élevés chez les patients ayant des céphalées de tension chroniques}

HISTORIQUE : La céphalée de tension est la principale forme de céphalée. Sa manifestation chronique, la céphalée de tension chronique (CTC), est l'une des plus difficiles à traiter. On comprend mal l'étiologie de la CTC, mais on pense qu'elle est multifactorielle et qu'elle varie selon les individus. Dans la présente étude, les auteurs ont cherché à déterminer les mécanismes courants de la pathologie de la CTC. Selon des études empiriques, diverses cytokines immunomodulatrices sont médiatrices des troubles de douleur chronique, y compris la CTC.

OBJECTIFS : Déterminer le rôle des cytokines périphériques et des facteurs génétiques dans l'apparition des CTC.

MÉTHODOLOGIE : Au moyen d'essais à billes cytométriques et du test ELISA, les chercheurs ont mesuré un groupe rationnel de cytokines qui, selon leur hypothèse, jouerait un rôle dans la pathogenèse des CTC, et ce, auprès de 56 personnes ayant des CTC et de 42 sujets témoins en santé de 18 à 65 ans.

RÉSULTATS : Les taux d'interleukine (IL)-1 $1 \beta$ étaient nettement plus élevés chez les participants à qui on avait diagnostiqué des CTC par rapport aux sujets témoins en santé, tandis que les taux d'IL-18 étaient nettement élevés chez les hommes ayant des CTC. Puisque les taux de ces médiateurs immuns étaient plus élevés en l'absence apparente de lésion ou d'infection, les auteurs ont cherché à déterminer si les changements génétiques étaient responsables des fluctuations des taux de cytokine. Ils ont analysé la réaction en chaîne de la polymérase et les polymorphismes de longueur des fragments de restriction pour déterminer les génotypes individuels à des positions clés des polymorphismes à nucléotide simple du gène IL-1B. Ils n'ont observé aucune association entre les CTC et les polymorphismes à nucléotide simple dans le gène l'IL-1 $\beta$.

CONCLUSIONS : D'après ces observations, des augmentations des cytokines pro-inflammatoires clés s'associent aux CTC, et la pathologie de la maladie inclut une inflammation neurovasculaire stérile.

However, what activates these peripheral trigger points is a matter of some debate.

Recent work involving chronic pain models in animal systems indicates that cytokines play a role not only in establishing and maintaining inflammation, but also in the generation and maintenance of some types of pain. In fact, recent work has implicated interleukin (IL) -6 as a factor in CTTH pain induction (6). Cytokines are believed to induce pain by directly binding to receptors on afferent neurons, including nociceptors. Proinflammatory cytokines, such as IL-1 $\beta$, IL-6 and tumour necrosis factor-alpha (TNF- $\alpha$ ), can directly activate nociceptive neurons, thereby generating action potentials and inducing pain hypersensitivity $(7,8)$.

The mechanisms by which cytokines alter neuronal excitability are the focus of ongoing investigations. Neurons, including peripheral sensory afferents as well as those in spinal cord dorsal horn, express receptors for cytokines (9). Neuronal excitability in the spinal dorsal horns is rapidly increased in response to these cytokines, suggesting a direct

${ }^{1}$ School of Pharmacy and Medical Sciences, University of South Australia, Adelaide; ${ }^{2}$ Centre for Applied Psychology, Faculty of Health, University of Canberra, Canberra; ${ }^{3}$ Discipline of Pharmacology, University of Adelaide; ${ }^{4}$ School of Health Sciences, University of South Australia, Adelaide, Australia

Correspondence: Dr Chris Della Vedova, School of Pharmacy and Medical Sciences, University of South Australia, Adelaide, South Australia 5000, Australia. Telephone 61-8-8302-2267, fax 61-8-8302-2389, e-mail chris.dellavedova@unisa.edu.au 
effect on neurons. For example, IL-1 $\beta$ enhances neuronal $N$-methyl-Daspartate (NMDA) conductance, including in the spinal cord dorsal horn (10). TNF- $\alpha$ rapidly upregulates membrane expression of neuronal 2-amino-3-(3-hydroxy-5-methyl-isoxazol-4-yl) propanoic acid (AMPA) receptors and increases AMPA conductance (11). TNF- $\alpha$ enhances neuroexcitability in response to glutamate, and IL-1 $\beta$ induces the release of the neuroexcitant ATP via an NMDA-mediated mechanism (12). In addition, proinflammatory cytokines can induce the production of a variety of neuroexcitatory substances, including nitric oxide, prostaglandins and reactive oxygen species (13). Thus, proinflammatory cytokines exert multiple effects, which are predicted both to increase neuronal excitation and enhance pain signalling.

Cytokine activity has also been found to correlate with acute experimental pain sensitivity in healthy individuals. IL-6 levels were found to be increased in the serum of healthy individuals after administration of noxious stimuli (heat and cold stimuli) (14). Similarly, a strong positive correlation between morphine-induced proliferation of peripheral blood mononuclear cells and tolerance to cold pressor pain has been reported, which indirectly suggests cytokine involvement in increased pain sensitivity through central nociceptive pathways (15). The proinflammatory cytokines IL- $1 \beta$ and TNF- $\alpha$ as well as IL- 6 were found to be associated with increased pain sensitivity in rats after intraplantar, intracerebroventricular or intrathecal injection (16), further highlighting the possibility that cytokines, in particular proinflammatory cytokines, may be important in increased acute experimental pain sensitivity observed in both animals and humans.

The present study examined the hypothesis that proinflammatory cytokines play a role in the pathophysiology of CTTH. To test this hypothesis, cytokine levels were measured in a population of individuals diagnosed with CTTH and compared with those of age- and sexmatched healthy control individuals. CTTH is not associated with any particular type of injury or infection. Therefore, it is not clear why levels of immune mediators should be elevated. One possibility is that CTTH patients carry genetic polymorphisms that lead to increased cytokine gene expression. To test this hypothesis, polymerase chain reaction (PCR) and restriction fragment length polymorphism (RFLP) analysis was used to determine individual genotypes at key single nucleotide polymorphism (SNP) positions in the IL-1 $1 \beta$ gene.

\section{Study population}

\section{METHODS}

Ethics approval for the present study was granted by the Human Research Ethics Committee at the University of South Australia (Adelaide, Australia). All participants were recruited from the general population via advertisements in local media requesting volunteers for a study on headaches. Informed consent was obtained from each study participant. For the CTTH group, 105 volunteers between 18 and 65 years of age were screened from the general population, with 56 meeting the inclusion criteria.

Forty-two healthy control participants between 18 and 65 years of age were recruited from the general population (Table 1). CTTH patients underwent a structured diagnostic interview based on the International Classification of Headache Disorders (ICHD), previously validated and used by the authors' group (17). Inclusion criteria for the CTTH group were: satisfying ICHD-II criteria for CTTH; not currently receiving (or having received in the last 12 months) intervention for headache; no psychiatric or major medical condition currently or in the last 12 months; and no comorbid headache or pain symptoms or diagnoses (other than CTTH) as previously described (18). Putative TTH volunteers taking analgesic medication other than $\leq 1000 \mathrm{mg}$ daily of acetylsalicylic acid or acetaminophen for more than 15 of 30 consecutive days of the previous 90 days were excluded from the present study. Age- and sex-matched healthy control subjects experienced no headache or other chronic pain activity in the past six months and $<10$ previous headaches. Subjects were required to be pain free on the day of testing and not have taken any analgesic medication for two weeks before testing or on the day of testing.
The Depression Anxiety Stress Scales-21

The Depression Anxiety Stress Scales-21 (DASS-21) is a 21-item selfreport questionnaire containing subscales for measuring levels of depression, anxiety and stress symptoms in healthy and clinical populations. Scores range from 0 to 42 for each subscale. The DASS has high internal consistency, and moderately high construct and convergent validity, detailed elsewhere (19).

\section{Headache diaries}

Participants were given a clinical diary detailed elsewhere (20) to record headache activity in for two weeks postinterview. The diary yields measures of mean headache intensity ( 0 to 5 scale), frequency (number of days on which headache occurred) and duration (h).

\section{Blood collection and processing}

Blood samples $(9 \mathrm{~mL})$ were collected via venipuncture by a phlebotomist nurse at the School of Psychology, University of South Australia. Blood was drawn between 09:00 and 11:00 in all patients to control for circadian variation in cytokine levels. Samples were collected in EDTA and serum-clotting tubes, and transported in biohazard containers to the Experimental Therapeutics Laboratory, Hanson Institute. The tubes were centrifuged at $2500 \times \mathrm{g}$ for $10 \mathrm{~min}$ at room temperature, and the blood components (serum, plasma, buffy coat cells) were aliquoted separately $(500 \mu \mathrm{L})$ into labelled $1.8 \mathrm{~mL}$ cryovials (Nunc, Denmark). The cryovials were snap frozen in liquid nitrogen and stored at $-70^{\circ} \mathrm{C}$ until analysis.

\section{Determination of cytokine levels}

Cytokine levels in serum samples were analyzed using an established cytometric bead array (CBA) kit (FlowCytomix; Bender MedSystems, Austria) according to the manufacturers' instructions. The kit reagents were diluted 1:2 for each run, and all samples were run in duplicate. The cytokines analyzed were interferon-gamma (IFN- $\gamma$ ), IL-1 $\beta$, IL-2, IL-4, IL-5, IL-6, IL-8, IL-10, IL-12p70, IL-18, TNF- $\alpha$ and TNF- $\beta$. Standard curves for each cytokine were included in each run, and sample concentrations were calculated using FlowCytomix Pro software.

To confirm IL-1 $\beta$ CBA results, an ELISA was performed using the BD OptEIA Human IL-1 $\beta$ ELISA kit (BD Biosciences, USA) according to the manufacturers' instructions. Coating buffer $(0.713 \mathrm{~g}$ sodium hydrogen carbonate, $0.159 \mathrm{~g}$ sodium carbonate, $\mathrm{pH}$ 9.5; quantum satis to $100 \mathrm{~mL})$, assay diluent $(1 \times$ phosphate buffered saline [PBS] with $10 \%$ fetal calf serum, $\mathrm{pH} 7.0$; quantum satis to $100 \mathrm{~mL}$ ) and wash buffer (1× PBS and $0.05 \%$ Tween-20) were freshly prepared. The TMB Substrate Set (BD Biosciences, USA) was used to produce the substrate solution for this assay as recommended $\left(\mathrm{H}_{2} \mathrm{O}_{2}, 3,3\right.$ ',5,5' tetramethylbenzidine) and $1 \mathrm{M}$ phosphoric acid was used as the stop solution. The standard curve and samples were analyzed in duplicate, and the absorbance of each sample was measured at $450 \mathrm{~nm}$ using a microplate reader (Ultra Microplate Reader EL808; BioTek Instruments Inc, USA).

\section{DNA isolation}

Genomic DNA of the participants was extracted and purified from previously aliquoted buffy coat cells using a commercially available DNA extraction kit (Purelink Genomic DNA Mini Kit; Invitrogen by Life Technologies, USA). Each genomic DNA sample was eluted to a total volume of $50 \mu \mathrm{L}$ and stored at $-20^{\circ} \mathrm{C}$ until analysis.

\section{IL-1B genotyping}

IL-1B genotypes at positions $-511,-31$ and +3954 were determined using PCR and RFLP assays as previously described (21). All PCR reactions were performed in a $50 \mu \mathrm{L}$ volume containing between $100 \mathrm{ng}$ and $200 \mathrm{ng}$ genomic DNA, $0.5 \mu \mathrm{mol} / \mathrm{L}$ of each primer and $1 \times$ DyNAzyme II PCR Master Mix (Finnzymes Oy, Finland; distributed by Thermo Fisher Scientific Australia Pty Ltd, Australia). The reactions were performed in a programmable thermal cycler (PTC-200, MJ Research Inc, Canada; distributed by GeneWorks Pty Ltd, 
TABLE 1

Sociodemographic data for chronic tension-type headache (CTTH) and healthy control (HC) groups

\begin{tabular}{|c|c|c|c|}
\hline & CTTH $(n=56)$ & $H C(n=42)$ & Test value \\
\hline Age, years & $45.5 \pm 13.4$ & $41.0 \pm 10.5$ & $1.92^{\S}$ \\
\hline Male sex, \% & $19 \pm 34$ & $18 \pm 43$ & $0.81^{\S}$ \\
\hline \multicolumn{4}{|l|}{ Headache characteristics* } \\
\hline Intensity (0-5) & $2.20 \pm 0.59$ & - & - \\
\hline $\begin{array}{c}\text { Frequency (number of } \\
\text { days of headache) }\end{array}$ & $10.0 \pm 3.5$ & - & - \\
\hline Duration, $\mathrm{h}$ & $7.62 \pm 5.3$ & - & - \\
\hline Stress $^{\dagger}$ & $16.5 \pm 8.2$ & $13.4 \pm 9.1$ & $1.76 \S$ \\
\hline Anxiety ${ }^{\dagger}$ & $7.7 \pm 7.3$ & $7.7 \pm 7.7$ & $0.01^{\S}$ \\
\hline Depression ${ }^{\dagger}$ & $9.4 \pm 7.9$ & $8.5 \pm 8.9$ & $0.48 \S$ \\
\hline
\end{tabular}

Data presented as mean $\pm S D$ unless otherwise indicated. *Headache activity from two-week headache diary; ${ }^{\dagger}$ Depression Anxiety Symptom Scale; It test, $d f=96$, except $\operatorname{sex}\left(\chi^{2}\right.$ test, $\left.d f=1\right) ; \S P>0.05$, two tailed

Australia) for $12 \mathrm{~min}$ at $94^{\circ} \mathrm{C}$ followed by 35 cycles of $94^{\circ} \mathrm{C}$ for $30 \mathrm{~s}$, $54^{\circ} \mathrm{C}$ for $1 \mathrm{~min}$ and $72^{\circ} \mathrm{C}$ for $30 \mathrm{~s}$, after which a final incubation at $72^{\circ} \mathrm{C}$ was performed.

For the RFLP analyses, the amplified products were digested using Aval for the IL- $1 \beta-511 \mathrm{C} \rightarrow \mathrm{T}\left(1 \mathrm{U}, 16 \mathrm{~h}\right.$ at $37^{\circ} \mathrm{C}$ and then $20 \mathrm{~min}$ at $80^{\circ} \mathrm{C}$; New England Biolabs, distributed by Genesearch Pty Ltd, Australia); AluI for IL-1 $\beta-311 \mathrm{~T} \rightarrow \mathrm{C}\left(1 \mathrm{U}, 16 \mathrm{~h}\right.$ at $37^{\circ} \mathrm{C}$ and then $20 \mathrm{~min}$ at $65^{\circ} \mathrm{C}$; New England Biolabs); and TaqI for IL-1 $\beta 3954 \mathrm{C} \rightarrow \mathrm{T}$ $\left(1 \mathrm{U}, 4 \mathrm{~h}\right.$ at $65^{\circ} \mathrm{C}$ and then $20 \mathrm{~min}$ at $80^{\circ} \mathrm{C}$; New England Biolabs). The digest products were visualized using gel electrophoresis on a $2 \%$ agarose gel. All assays were run with no-template negative controls to ensure that contamination was not present.

Statistical analysis

Differences between groups in age, stress, anxiety and depression were examined using independent groups $t$ tests. The $\chi^{2}$ test was used to examine group differences in sex ratios.

Results of the cytokine levels were expressed as mean \pm SEM. The statistical analyses were performed using GraphPad Prism version 5.01 (GraphPad Software, USA). Cytokine levels were assessed using the unpaired two-tailed $t$ test or Mann-Whitney test as appropriate, after first assessing the data for normality using the D'Agostino and Pearson omnibus normality test. The significance threshold for all results was set to $\mathrm{P}<0.05$.

Genotype distribution was examined for significant departure from Hardy-Weinberg equilibrium using the $\chi^{2}$ test. Allele frequencies between the groups were compared using the Fisher's exact test with ORs and $95 \%$ CIs. OR (95\% CI) data were converted to effect size and SE. Genotype frequencies between groups were compared using the $\chi^{2}$ test; $\mathrm{P} \leq 0.05$ was considered to be statistically significant.

\section{RESULTS}

Sociodemographic and headache data for CTTH and healthy individuals

There were no significant differences between the groups on measures of age, stress, depression or anxiety (Table 1). Stress and depression levels were in the normal range for both groups, while both groups had anxiety levels bordering normal to mild. Headache profiles for the CTTH group are presented in Table 2 .

Serum cytokine levels in CTTH compared with healthy individuals Levels of IL-1 $\beta$, IL-2, IL-4, IL-5, IL-6, IL-8, IL-10, IL-12, IL-18, IFN- $\gamma$, TNF- $\alpha$ and TNF- $\beta$ were measured using a CBA kit in CTTH patients and healthy control individuals (Figure 1). Levels of IL-4 and IL-12 were higher in healthy controls compared with CTTH individuals; however, these results were not statistically significant $(\mathrm{P}=0.20$ and $\mathrm{P}=0.25$,
TABLE 2

Headache profiles in the chronic tension-type headache group

\begin{tabular}{lc}
\hline Profile characteristic & $\mathbf{n ~ ( \% )}$ \\
\hline Bilateral location & $38(68)$ \\
Pressing/tightening quality & $47(84)$ \\
Mild to moderate intensity & $50(89)$ \\
Aggravated by routine physical activity & $16(29)$ \\
Nausea & $12(21)$ \\
Vomiting & $0(0)$ \\
Phonophobia & $17(30)$ \\
Photophobia & $13(23)$ \\
\hline
\end{tabular}

The mean ( $\pm S D$ ) duration of illness was $19.9 \pm 13.8$ years

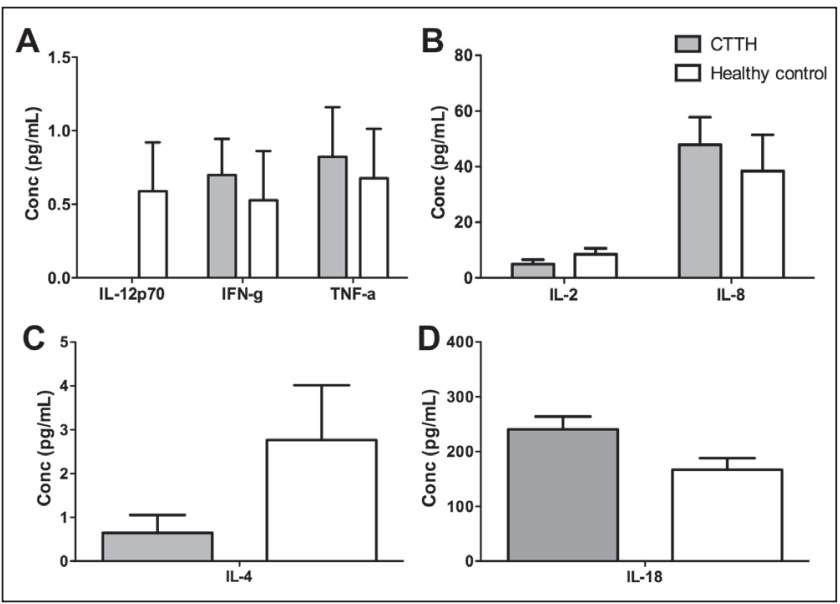

Figure 1) Comparison of secreted cytokine levels in chronic tension-type headache (CTTH) individuals and healthy controls. Serum cytokine levels as measured by cytometric bead array in CTTH individuals (grey) and healthy control individuals (white) ( $P>0.05)$. Conc Concentration; IFN-g Interferon-gamma; IL Interleukin; TNF-a Tumour necrosis factor-alpha

respectively). Similarly, nonsignificant increases in TNF- $\alpha$, IFN- $\gamma$ and IL-8 levels were observed in CTTH individuals relative to healthy controls. Levels of IL-5, IL-6, IL-10 and TNF- $\beta$ were not detectable in the present assay. Serum IL-18 levels were notably higher in CTTH patients compared with healthy controls (Figure 1D). The mean value for healthy individuals was $125.8 \pm 15.70(n=38)$ with the mean for CTTH individuals being $162.7 \pm 13.85(\mathrm{n}=56)$. This difference, however, was not statistically significant $(\mathrm{P}=0.09)$.

Serum IL-1 $\beta$ levels in CTTH compared with healthy individuals As measured by CBA, IL- $1 \beta$ levels were significantly higher in CTTH patients compared with healthy individuals $(\mathrm{P}=0.03)$ (Figure 2A). However, CBA measurements were near the lower limit of detection; thus, an ELISA assay was performed to confirm the significance of these results. ELISA results confirmed those obtained by CBA, with IL-1 $\beta$ levels significantly higher in CTTH patients than negative controls $(\mathrm{P}<0.001)$ (Figure $2 \mathrm{~B})$.

Sex differences in cytokine levels in CTTH compared with healthy individuals

Because CTTH exhibits a significantly higher prevalence in women than men, cytokine levels were analyzed according to sex. Male CTTH individuals were compared with healthy male controls and female CTTH individuals with healthy female controls. There were no significant sex differences in levels of IL-1 $\beta$, IL-2, IL-4, IL-8, IL-12, IFN- $\gamma$ or TNF- $\alpha$ between CTTH and healthy control individuals. IL-5, IL- 6, IL-10 and TNF- $\beta$ were not detectable. However, male CTTH patients exhibited significantly higher levels of IL-18 than healthy males (two-tailed $t$ test, $\mathrm{P}=0.0436$ ), while the difference in IL-18 levels in female participants was not significant 


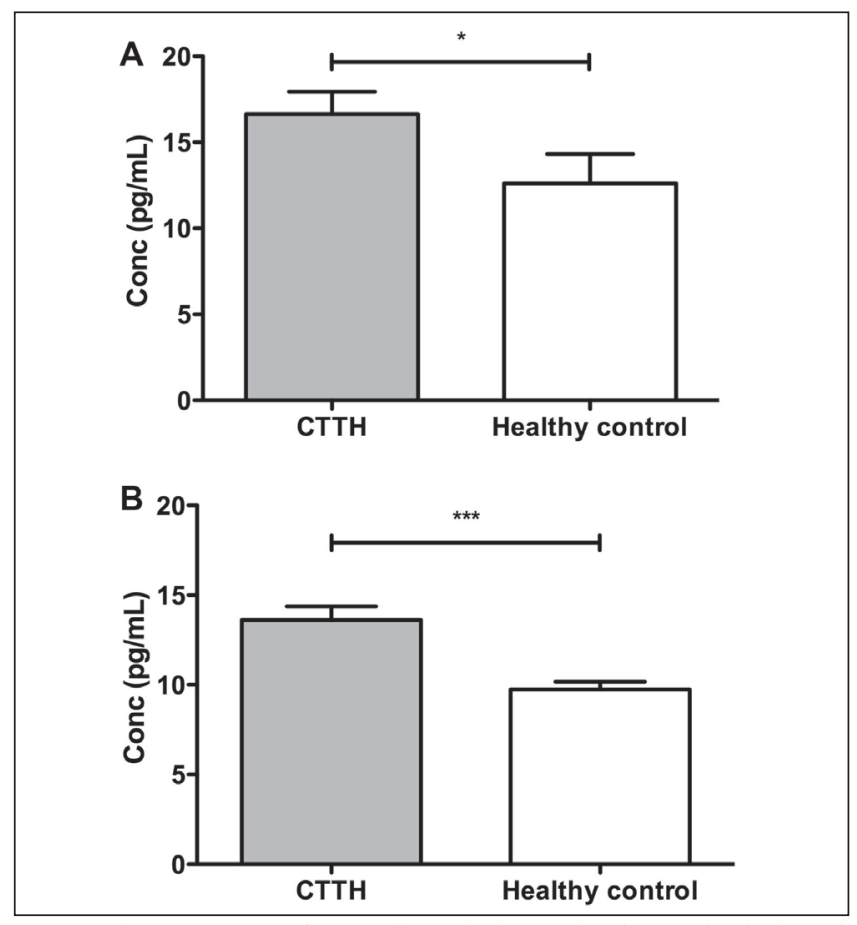

Figure 2) Comparison of secreted interleukin-1 $\beta$ levels in individuals with chronic tension-type headache (CTTH) and healthy control individuals. Serum cytokine levels as measured by cytometric bead array (A) and ELISA (B) in CTTH individuals (grey) and healthy control individuals (white). *Cytokine bead array, $P=0.04$; **ELISA, $P<0.001$. Conc Concentration

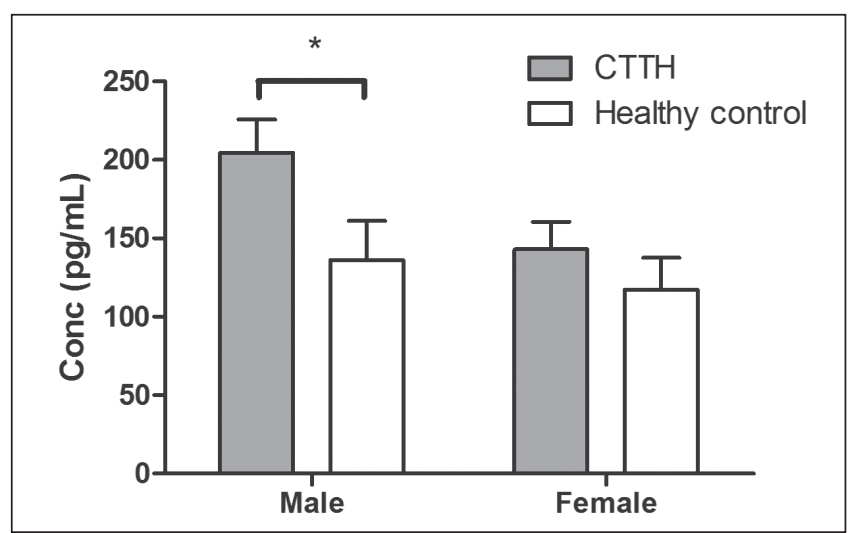

Figure 3) Comparison of secreted interleukin-18 levels by sex in individuals with chronic tension-type headache (CTTH) and healthy control individuals. Serum interleukin-18 levels as measured by cytometric bead array in male and female individuals with CTTH (grey) and healthy control individuals (white). Male, $P=0.0436$; female, $P=0.432$. Conc Concentration

(Figure 3). However, IL-18 levels were positively correlated with IL-1 $\beta$ levels regardless of sex (Spearman correlation, $r_{s}=0.281$, $\mathrm{P}=0.01$ ).

Correlation of IL-1 $\beta$ and IL-18 levels with headache profiles

Relationships between IL-1 $\beta$ and IL-18 levels and headache activity were examined using Pearson's $r$ correlations. Neither IL-1 $\beta$ nor IL-18 levels were significantly correlated with headache intensity, frequency or duration as recorded in the headache diary (all $\mathrm{P}<0.05$ ).

\section{IL-1B genotyping}

There were no significant differences in allele frequency (data not shown) or genotype frequencies (Table 3 ) in any of the three IL-1B SNPs analyzed. While CTTH patients were more likely to be
TABLE 3

Comparison of interleukin-1 $\beta$ genotype frequencies between chronic tension-type headache (CTTH) and healthy control groups

\begin{tabular}{lcrrrr}
\hline SNP & Genotype & \multicolumn{1}{c}{ CTTH } & $\begin{array}{r}\text { Healthy } \\
\text { control }\end{array}$ & $\mathbf{X}^{2}$ & $\mathbf{P}$ \\
\hline-511 & $\mathrm{C} / \mathrm{C}$ & $1(2.0)$ & $0(0.0)$ & & \\
& $\mathrm{C} / \mathrm{T}$ & $32(64)$ & $21(62)$ & 0.80 & 0.67 \\
& $\mathrm{~T} / \mathrm{T}$ & $17(34)$ & $13(38)$ & & \\
-31 & $\mathrm{~T} / \mathrm{T}$ & $6(12)$ & $1(2.9)$ & & \\
& $\mathrm{T} / \mathrm{C}$ & $12(24)$ & $12(35)$ & 2.9 & 0.23 \\
3954 & $\mathrm{C} / \mathrm{C}$ & $32(64)$ & $21(62)$ & & \\
& $\mathrm{C} / \mathrm{C}$ & $30(54)$ & $22(59)$ & & \\
& $\mathrm{C} / \mathrm{T}$ & $10(18)$ & $4(11)$ & 0.9 & 0.6 \\
& $\mathrm{~T} / \mathrm{T}$ & $16(29)$ & $11(30)$ & & \\
\hline
\end{tabular}

Data presented as $n(\%)$ unless otherwise indicate. $P$ values are corrected for false discovery rate. SNP Single nucleotide polymorphism

homozygous for the $\mathrm{T} / \mathrm{T}$ genotype at $\mathrm{IL}-1 \mathrm{~B}-31 \mathrm{~T} \rightarrow \mathrm{C}$ locus, this was merely a trend in this population. Neither were levels of IL-1B expression, as assessed using ELISA or CBA, across the two groups related to genotype in this sample population (data not shown).

\section{DISCUSSION}

The chronic daily form of TTH is considered to be one of the more treatment-resistant headache syndromes and, thus, a mechanistic understanding of its pathogenesis is highly desirable. Previous studies have found that there is a significant increase in proinflammatory cytokine levels and a decrease in anti-inflammatory cytokine levels in some chronic pain disorders in humans $(22,23)$. In fact, the proinflammatory cytokine IL- 6 has been shown to be increased in individuals with both the episodic and chronic forms of TTH (6). We sought to determine the roles that inflammatory mediators play in the development of CTTH.

The results of the present study reveal that serum IL-1 $\beta$ levels are increased in CTTH individuals compared with healthy controls. Nociceptors express receptors for cytokines, chemokines and other inflammatory mediators that are produced in inflamed tissues, and are able to respond to these mediators (7). IL-1 $\beta$ is one of several mediators that can cause action potential discharge by increasing sodium and calcium currents at the peripheral terminal through postreceptor signalling cascades (24). In addition, IL-1 $\beta$ enhances neuronal NMDA conductance and can induce the release of ATP, a neuroexcitant, via an NMDA-mediated mechanism (12). The release of these inflammatory mediators also acts on the microglial cells in the central nervous system, initiating an internal mechanism to enhance cytokine expression and the propagation of this signalling cascade in the central nervous system (25). Increased levels of IL-1 $\beta$ have also been found to be elevated in jugular vein blood during migraine attacks $(26,27)$. IL-1 $\beta$ may play a causative role in migraine by activating neuronal and glial cells to release cyclo-oxygenase-2 (28), which in turn could induce neuroinflammation. However, the roles for sterile inflammation are likely distinct between TTH and migraine. The levels of $\mathrm{N}$-acetyl-aspartate, a biomarker of neuronal integrity, are significantly lower in migraine than in TTH, suggesting that migraine involves some level of neuronal degradation that is not a factor in $\mathrm{TTH}(29,30)$.

There was a trend toward an increase in serum IL-18 levels in CTTH individuals compared with healthy controls and a statistically significant increase in IL-18 levels in male CTTH individuals. IL-18 levels were also found to be positively correlated with IL-1 $\beta$ levels, suggesting that these two proinflammatory cytokines are regulated in a similar manner. Nevertheless, the relatively small number of patients should be considered to be a limitation of the present study. IL-18 is a proinflammatory cytokine that is structurally homologous to but functionally distinct from IL-1 $\beta$ (31). In relation to this chronic pain study, both microglia and astrocytes in the central nervous system have been 
found to secrete functional IL-18. In addition, in vitro IL-18 stimulates the production of IL-1 $\beta$ in astrocytes and blood mononuclear cells, indicating that IL-18 may play a role in modulating IL-1 $\beta$ (32). In the present study, the increase in IL- $1 \beta$ levels in CTTH individuals may occur as a result of the apparent increase in IL-18 levels.

IL-1 $\beta$ and IL-18 are typically released in response to tissue injury or pathogen infection, which has not been demonstrably implicated in cases of CTTH. However, family studies have shown that genetic factors are important in the etiology of CTTH (33). We hypothesized that genetic changes may be responsible for the observed increase in IL-1 $\beta$ expression observed in CTTH individuals. As a complex trait, CTTH would be expected to have a polygenic nature modified by environmental stressors. A number of chronic pain conditions have been found to be associated with genetic polymorphisms, including genes that code for cytokines or their receptors (34). Therefore, one possibility is that CTTH patients carry genetic polymorphisms that lead to increased gene expression of IL-1B. Several SNPs have been identified in the IL-1B gene that may affect $I L-1 B$ expression including two promoter polymorphisms $I L-1 B \quad-511 \mathrm{C} \rightarrow \mathrm{T} \quad(\mathrm{rs} 16944)$ and $I L-1 B \quad-31 \mathrm{~T} \rightarrow \mathrm{C}$ (rs1143627), and the coding region polymorphism IL-1B 3954C $\rightarrow \mathrm{T}$ (rs1143634). These IL-1B polymorphisms have been linked to a number of neurobehavioural conditions including impaired emotion processing in major depression (35), alcoholism and opioid dependence (21), as well as chronic pain conditions such as vulvar vestibulitis syndrome (36) and burning mouth syndrome (37). We did not find an association between three functional SNPs in the IL-1B gene and CTTH. We did intentionally select polymorphic loci that have been shown to result in changes in IL-1B gene expression, with the expectation that a mutation in the promoter of the gene may result in an increase or decrease in transcription. However, the small study population is a limitation in this type of association analysis. In addition, upstream regulators of IL-1B transcription could be responsible for the changes in serum levels that we detected.

\section{REFERENCES}

1. Zagami AS. Chronic tension-type headache. CNS Drugs 1995;4:90-98.

2. Schwartz BS, Stewart WF, Simon D, Lipton RB. Epidemiology of tension-type headache. JAMA 1998;279:381-3.

3. Fumal A, Schoenen J. Tension-type headache: Current research and clinical management. Lancet Neurol 2008;7:70-83.

4. Langemark M, Bach FW, Jensen TS, Olesen J. Decreased nociceptive flexion reflex threshold in chronic tension-type headache. Arch Neurol 1993;50:1061-4.

5. Ailani J. Chronic tension-type headache. Curr Pain Headache Rep 2009; 13:479-83.

6. Koçer A, Koçer E, Memişoğullari R, Domaç FM, Yüksel H. Interleukin-6 levels in tension headache patients. Clin J Pain 2010;26:690-3.

7. Binshtok AM, Wang H, Zimmermann K, et al. Nociceptors are interleukin-1beta sensors. J Neurosci 2008;28:14062-73.

8. Schaible HG, von Banchet GS, Boettger MK, et al. The role of proinflammatory cytokines in the generation and maintenance of joint pain. Ann N Y Acad Sci 2010;1193:60-9.

9. Ohtori S, Takahashi K, Moriya H, Myers RR. TNF-alpha and TNF-alpha receptor type 1 upregulation in glia and neurons after peripheral nerve injury: Studies in murine DRG and spinal cord. Spine (Phila Pa 1976), 2004:29:1082-8.

10. Samad TA, Wang H, Broom DC, Woolf CJ. Central neuroimmune interactions after peripheral inflammation: Interleukin1-b potentiates synaptic transmission in the spinal cord. Proc Soc Neurosci 2004;34:511-7.

11. Stellwagen D, Beattie EC, Seo JY, Malenka RC. Differential regulation of AMPA receptor and GABA receptor trafficking by tumor necrosis factor-alpha. J Neurosci 2005;25:3219-28.

12. Sperlágh B, Baranyi M, Haskó G, Vizi ES. Potent effect of interleukin-1 beta to evoke ATP and adenosine release from rat hippocampal slices. J Neuroimmunol 2004;151:33-9.

13. Hucho T, Levine JD. Signaling pathways in sensitization: Toward a nociceptor cell biology. Neuron 2007;55:365-76.

14. Edwards RR, Kronfli T, Haythornthwaite JA, McGuire L, Page GG. Association of catastrophizing with interleukin- 6 responses to acute pain. Pain 2008;140:135-44.

\section{CONCLUSION}

We have shown that IL-1 $\beta$ levels are increased in CTTH individuals as well as an increase in IL-18 expression in males. We propose a model in which the elevation in peripheral proinflammatory cytokine levels leads to an increase in neuronal conduction in peripheral nociceptive neurons and, thus, increased peripheral nociceptive input, which may contribute to central sensitization and the enhanced general hyperalgesia that are well documented in CTTH $(18,38)$. The potential involvement of these two early immune mediators suggests a role for the inflammasome in CTTH pathophysiology, and future work examining the role of inflammasome components, such as caspase-1, could provide insight into a potential role of sterile tissue injury in CTTH.

\section{SUMMARY}

The etiology of CTTH is not well understood. In the present study, we sought to identify common mechanisms of CTTH pathology. Proinflammatory cytokines have been proposed to play a role in the generation and maintenance of some types of pain. We show that levels of the proinflammatory cytokine IL-1 $\beta$ are increased in CTTH individuals. We propose a model in which the elevation in peripheral proinflammatory cytokine levels leads to an increase in neuronal conduction in peripheral nociceptive neurons and, thus, increased peripheral nociceptive input, which may contribute to central sensitization and the enhanced general hyperalgesia common in CTTH.

ACKNOWLEDGEMENTS: This project was funded by a research grant from the Medical Advances Without Animals Trust. Alan Dohnalek was supported by a Royal Adelaide Hospital Honours Scholarship. Vanessa Lee was supported by a University of South Australia High Achiever Summer Vacation Scholarship. Mark Hutchinson holds an Australian Research Council Australian Research Fellowship (DP110100297).

15. Hutchinson MR, La Vincente SF, Somogyi AA. In vitro opioid induced proliferation of peripheral blood immune cells correlates with in vivo cold pressor pain tolerance in humans: A biological marker of pain tolerance. Pain 2004;110:751-5.

16. Sommer C, Kress M. Recent findings on how proinflammatory cytokines cause pain: Peripheral mechanisms in inflammatory and neuropathic hyperalgesia. Neurosci Lett 2004;361:184-7.

17. International Headache Society, The International Classification of Headache Disorders: 2nd Edition (ICHD II). Cephalalgia (Supplement) 2004;24:9-160

18. Cathcart S, Winefield AH, Lushington K, Rolan P. Noxious inhibition of temporal summation is impaired in chronic tensiontype headache. Headache 2010;50:403-12.

19. Lovibond SH, Lovibond PF. Manual for the Depression Anxiety Stress Scales, 2nd edn. 1995, Sydney: Psychology Foundation.

20. Cathcart S, Pritchard D. Relationships between arousal-related moods and episodic tension-type headache: A biopsychological study. Headache 1998;38:214-21.

21. Liu L, Hutchinson MR, White JM, Somogyi AA, Coller JK. Association of IL-1B genetic polymorphisms with an increased risk of opioid and alcohol dependence. Pharmacogenet Genomics 2009;19:869-76.

22. Backonja MM, Coe CL, Muller DA, Schell K. Altered cytokine levels in the blood and cerebrospinal fluid of chronic pain patients. J Neuroimmunol 2008;195:157-63.

23. Uçeyler N, Valenza R, Stock M, Schedel R, Sprotte G, Sommer C. Reduced levels of antiinflammatory cytokines in patients with chronic widespread pain. Arthrit Rheum 2006;54:2656-64.

24. Costigan M, Scholz J, Woolf CJ. Neuropathic pain: A maladaptive response of the nervous system to damage. Ann Rev Neurosci 2009;32:1-32.

25. Marchand F, Perretti M, McMahon SB. Role of the immune system in chronic pain. Nat Rev Neurosci 2005;6:521-32.

26. Perini F, D'Andrea G, Galloni E, et al. Plasma cytokine levels in migraineurs and controls. Headache 2005;45:926-31.

27. Sarchielli P, Alberti A, Baldi A, et al. Proinflammatory cytokines, adhesion molecules, and lymphocyte integrin expression in the 
internal jugular blood of migraine patients without aura assessed ictally. Headache 2006;46:200-7.

28. Neeb L, Hellen P, Boehnke C, et al. IL-1beta stimulates COX-2 dependent PGE(2) synthesis and CGRP release in rat trigeminal ganglia cells. PLoS One 2011;6:e17360.

29. de Tommaso M, Ceci E, Pica C, et al. Serum levels of N-acetylaspartate in migraine and tension-type headache. J Headache Pain 2012;13:389-94.

30. Lionetto L, Capi M, Vignaroli G, Negro A, Martelletti P.

Deciphering the task of $\mathrm{N}$-acetyl aspartate in migraine. Exp Rev Neurotherapeut 2012;12:1057-9.

31. Nakanishi K, Yoshimoto T, Tsutsi H, Okamura H. Interleukin-18 is a unique cytokine that stimulates both Th1 and Th2 responses depending on its cytokine milieu. Cytokine Growth Factor Rev 2001;12:53-72.

32. Netea MG, Simon A, van de Veerdonk F, Kullberg BJ, Van der Meer JW, Joosten LA. IL-1beta processing in host defense: Beyond the inflammasomes. PLoS Pathog 2010;6:e1000661.

33. Russell MB, Levi N, Kaprio J. Genetics of tension-type headache: A population based twin study. Am J Med Genet B Neuropsychiatr Genet 2007;144B:982-6.
34. Diatchenko L, Nackley AG, Tchivileva IE, Shabalina SA, Maixner W. Genetic architecture of human pain perception. Trends Genet 2007;23:605-13.

35. Baune BT, Dannlowski U, Domschke K, et al. The interleukin 1 beta (IL1B) gene is associated with failure to achieve remission and impaired emotion processing in major depression. Biol Psychiatry 2010;67:543-9.

36. Gerber S, Bongiovanni AM, Ledger WJ, Witkin SS. Interleukin1beta gene polymorphism in women with vulvar vestibulitis syndrome. Eur J Obstet Gynecol Reprod Biol 2003;107:74-7.

37. Guimarães AL, de Sá AR, Victoria JM, de Fátima Correia-Silva J, Gomez MV, Gomez RS. Interleukin-1beta and serotonin transporter gene polymorphisms in burning mouth syndrome patients. J Pain 2006;7:654-8

38. Ashina S, Lyngberg A, Jensen R. Headache characteristics and chronification of migraine and tension-type headache: A population-based study. Cephalalgia 2010;30:943-52. 


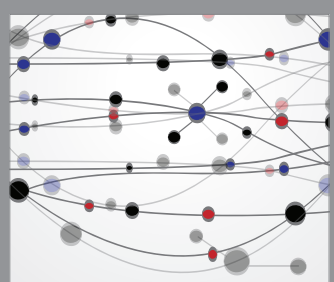

The Scientific World Journal
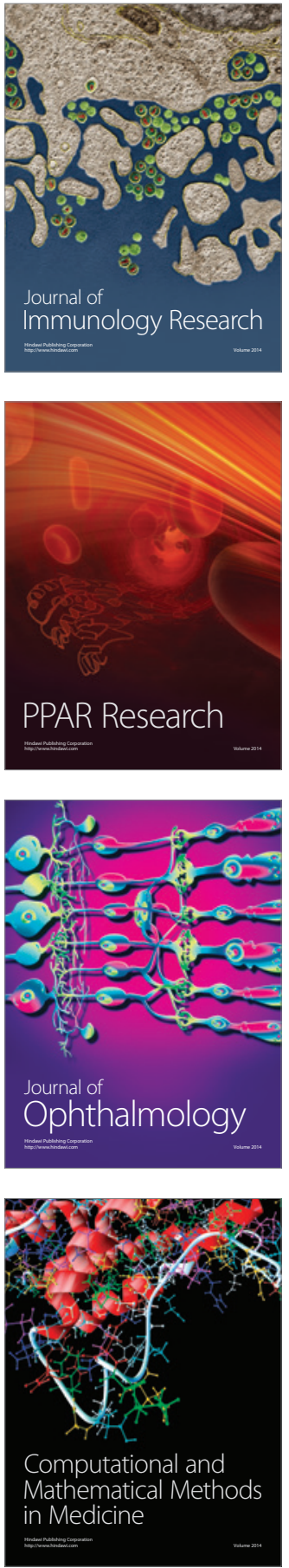

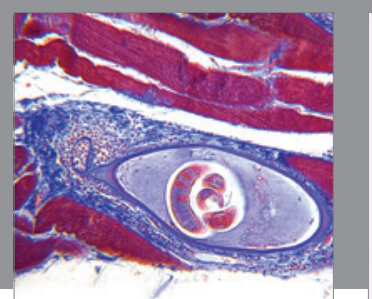

Gastroenterology Research and Practice

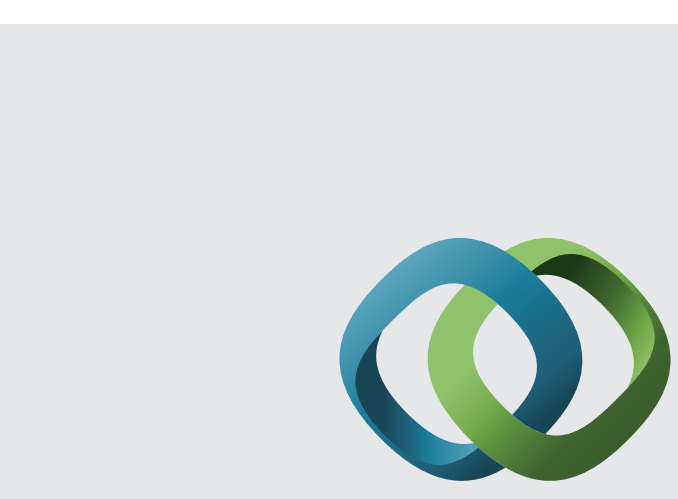

\section{Hindawi}

Submit your manuscripts at

http://www.hindawi.com
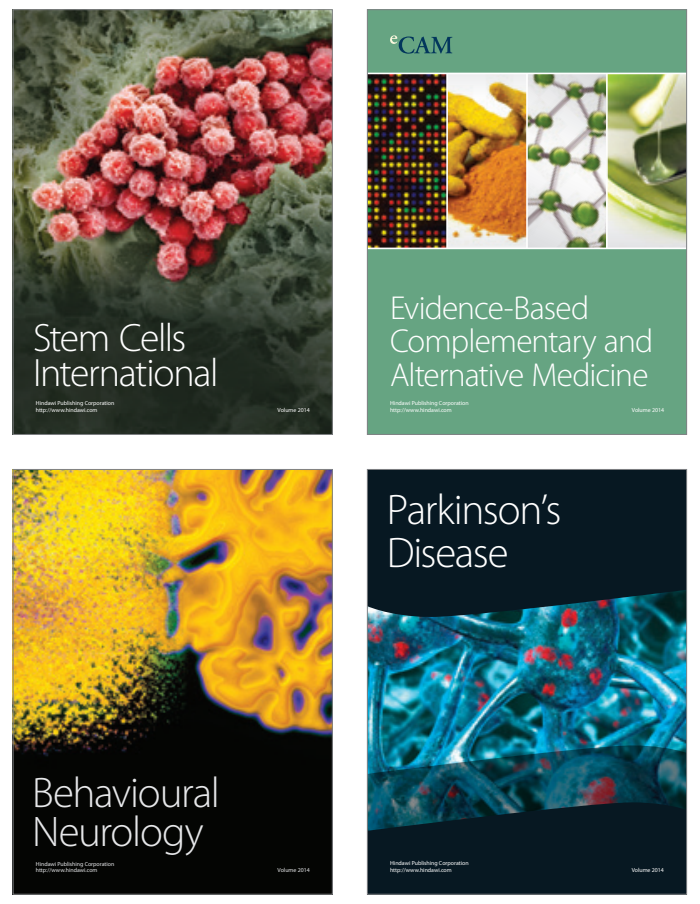
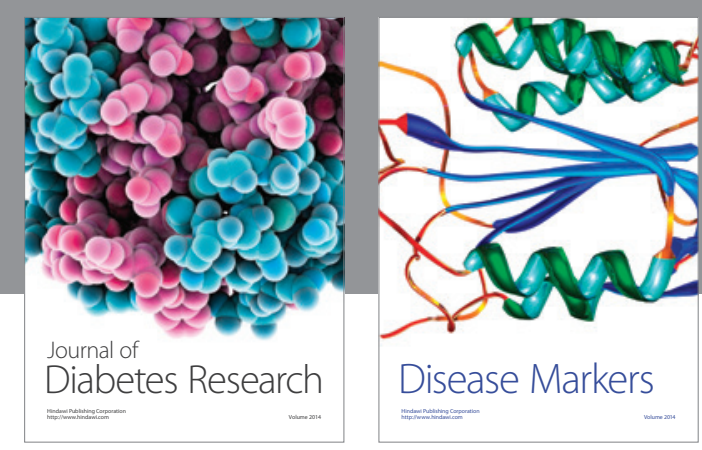

Disease Markers
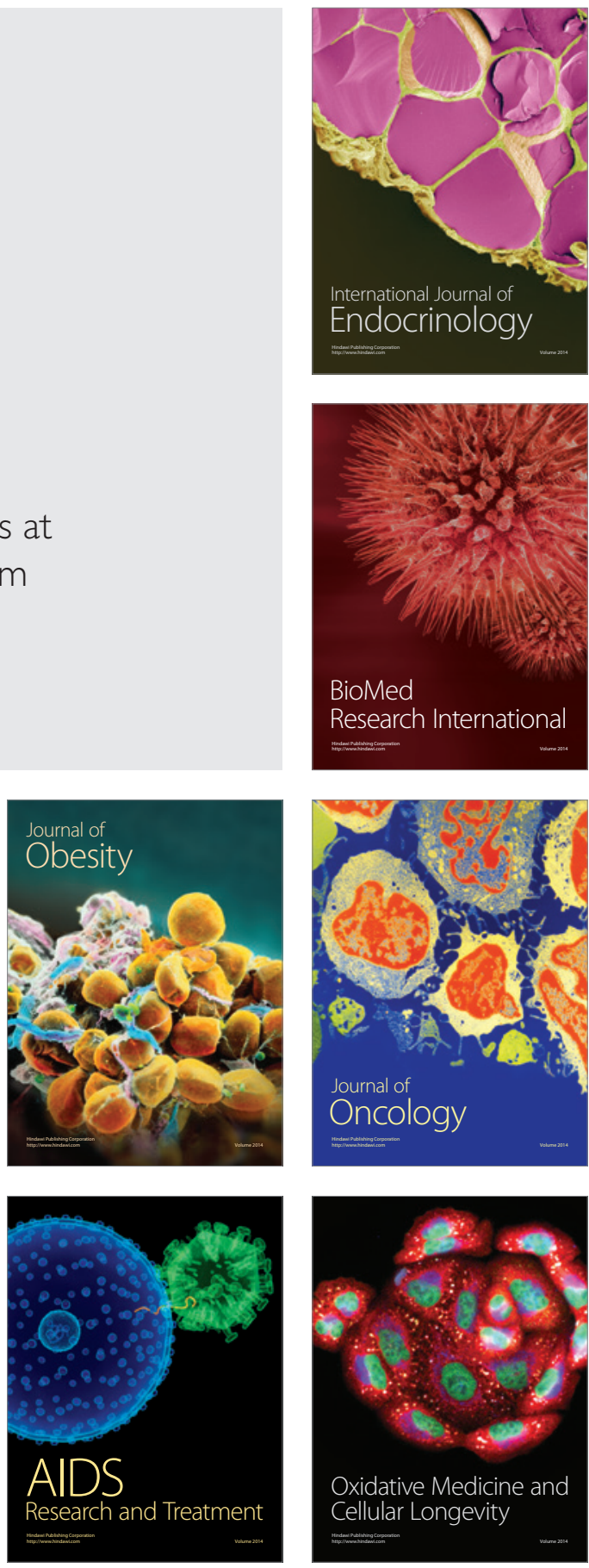